University of South Florida

DIGITAL COMMONS

Digital Commons @ University of

@ UNIVERSITY OF SOUTH FLORIDA

South Florida

Rehabilitation and Mental Health Counseling

Faculty Publications

Rehabilitation and Mental Health Counseling

2012

\title{
Something in the Way She Moves: Falls and Fractal Dimension
}

\author{
William D. Kearns \\ University of South Florida, kearns@usf.edu \\ James L. Fozard PhD \\ University of South Florida, jfozard@usf.edu
}

M. A. Becker

C. Dion

J. Craighead

See next page for additional authors

Follow this and additional works at: https://digitalcommons.usf.edu/mhs_facpub

\section{Scholar Commons Citation}

Kearns, William D.; Fozard, James L. PhD; Becker, M. A.; Dion, C.; Craighead, J.; and Jasiewicz, J., "Something in the Way She Moves: Falls and Fractal Dimension" (2012). Rehabilitation and Mental Health Counseling Faculty Publications. 112.

https://digitalcommons.usf.edu/mhs_facpub/112

This Article is brought to you for free and open access by the Rehabilitation and Mental Health Counseling at Digital Commons @ University of South Florida. It has been accepted for inclusion in Rehabilitation and Mental Health Counseling Faculty Publications by an authorized administrator of Digital Commons @ University of South Florida. For more information, please contact digitalcommons@usf.edu. 


\section{Authors}

William D. Kearns, James L. Fozard PhD, M. A. Becker, C. Dion, J. Craighead, and J. Jasiewicz 


\section{Track: Housing - Building - Daily living Symposium: The sensitive residence}

W.D. KEARNS, J.L. FOZARD (Conveners). The sensitive residence: Predicting health changes using sensor networks. Gerontechnology 2012;11(2):272; doi:10.4017/gt.2012.11.02.047.00 Participants: C. Galambos, T. HAyES, W.D. KEARNS, S. SundaRRAO (all from USA). ISSUE The desire of people to age in place - in their own homes - must be weighed against the declines in physical and cognitive functioning that occurs in the aged. This symposium informs on technology-based measurement systems that monitor activities in everyday living environments and which provide information predictive of health changes. The goal of such research is to provide a basis for preventive or compensatory interventions supporting continued functional independence into old age. CONTENT The technologies discussed include a variety of in-home sensing technologies ranging from passive motion detection to sophisticated Real Time Location Systems location aware devices capable of distinguishing among multiple individuals in a single setting. The format of this forum helps to elucidate the role these technologies play in data collection and in home health service systems delivery. It also illustrates several approaches to addressing privacy, technology acceptance, reliability, validity, and the integration of systems into more comprehensive systems of care which are unique to monitoring a person's movements in home and community based settings. The research goals to be discussed include sensing physical and cognitive functional changes which may indicate declining health. The presentations address the use of location-aware technology in home and congregate living settings. STRUCTURE Drs. Kearns, Fozard, Becker, \& Dion, (University of South Florida), Craighead \& Jasiewicz (US Dept. of Veterans Affairs) will present 'Something in the way she moves: Falls and fractal dimension' describing new research showing fractal dimension, a measure of everyday movement path tortuosity which has been demonstrated to be highly negatively correlated with the geographical orientation subscale of the Mini Mental Status Exam (MMSE) and may be useful as a predictor of falls in older persons. Professors Galambos, Skubic, Wang, \& Rantz (University of Missouri) will present 'Using density map visualization for early detection and management of dementia and depression'. Professors Stephen Sundarrao and Don Dekker (University of South Florida) will present 'The use of sensor integrated recreational technologies to monitor and enhance balance and coordination in older persons'. In this context sensors are used as feedback devices and also to monitor health changes in physically active older adults. Finally, professors Tamara Hayes, Jeff Kaye, Misha Pavel and Holly Jimison (University of Oregon Health Sciences University) will present "The human activity project: What behavioral markers teach us about important health changes'. CONCLUSION The presentations highlight advances in location aware technologies to monitor movement patterns in home settings. The overall goal is to relate changes in movement patterns to changes in health in home settings. Improved home monitoring may forestall older persons transitioning to more expensive formal care settings thereby maintaining their independence.

Keywords: housing \& daily living, location aware technologies, human movement patterns, sensor technologies

Affiliation: University of South Florida, Tampa, Florida, USA; E: kearns@usf.edu

\section{W.D. KEARNS, J.L. FOZARD, M. BECKER, C. DION, J. CRAIGHEAD, J.M. JASIEWICZ. Something in the way}

she moves: Falls and fractal dimension. Gerontechnology 2012;11(2):272-273; doi:10.4017/ gt.2012.11.02.188.00 Purpose Falls are very expensive events, costing the US\$19 billion annually ${ }^{1}$. Standardized gait and balance tests are expensive to perform, have limited predictive capability, and cannot be performed on those who cannot stand or walk. A measure of movement path variability (tortuosity) called fractal dimension (D) derived from ultra-wideband RTLS-sensor data recorded on assisted living facility (ALF) residents has been linked to cognitive decline and may provide a means to link fall risk to cognitive decline ${ }^{2}$. Increased D provided by the residential RTLS-sensor system may provide ALF-administrators with an early warning mechanism that a resident is at a heightened risk for falls by automatically calculating fall risk from movement variability data. Method Subjects: 53 ALF-residents at two sites (44 female, mean age 75.5 yrs, $\mathrm{SD}=11.6)$ with mean MMSE of $18(\mathrm{SD}=7.0)$. Apparatus: ubisense real-time location tracking system with $X, Y$ resolution to $+/-20 \mathrm{~cm}$. Measures: time and distance moved 7 days before each fall, and fractal dimension (D) a path variability index derived from movement data. The number of psychoactive medications prescribed at the time of the fall was also recorded. Procedure: sub- 
jects either wore a small, lightweight transponder on a comfortable wrist-strap or on their assistive device for 1 year. while movements in a common use area were tracked and falls tabulated from ALF-records. Twenty-three residents who fell had RTLS-movement data in the 7 days prior to their index fall. For non-fallers their recording interval's midpoint served as a reference date from which 7 days of RTLS movement data was gathered. Results \& Discussion Fallers and nonfallers did not differ in total time or distance traveled in the 7 days before falling; however mean $D$ levels were significantly higher in fallers than non-fallers $(1.30 \mathrm{vs} .1 .25 ; \mathrm{t}=1.827 \mathrm{df}=51$ $p=0.037$ [one tailed]). A logistic regression revealed the odds of falling were $3.85(p=0.009)$ times greater for every 0.1 increase in $\mathrm{D}$ and longer paths were associated with a 0.97 reduction in fall risk $(p=0.042)$ while having a fall in the prior year increased the risk of falling by 5.08 $(p=0.023)$. There was a strong trend toward increased risk of falling (odds increased 6.13, $p=0.06$ ) if psychoactive medications were being taken at the time of the fall. Elevated fall risk over time may be estimable by realtime monitoring using unobtrusive sensors allowing timely preventive intervention by providers.

\section{References}

1. Stevens JA, Corso PS, Finkelstein EA, Miller TR. The costs of fatal and non-fatal falls among older adults. Injury Prevention 2006;12(5):290-295; doi:10.1136/ip.2005.011015

2. Kearns WD, Fozard JL, Nams VO, Craighead JD. Wireless telesurveillance system for detecting dementia. Gerontechnology 2011;10(2):90-102; doi:10.4017/ gt.2011.10.2.004.00

Keywords: housing \& daily living, location aware technologies, human movement patterns, sensor technologies

Affiliation: University of South Florida, Tampa, Florida, USA; E: kearns@usf.edu Full paper: No

\section{GALAMBOS, M. SKUBIC, S. WANG, M. RANTZ. Using density map visualization for early detection}

and management of dementia and depression. Gerontechnology 2012;11(2):273-274; doi:10.4017/gt.2012.11.02.105.00 Purpose The purpose of the study is to investigate whether motion density maps based on passive infrared (PIR) motion sensors and the dissimilarity measure of the density maps, along with relative energy expenditure estimates derived from motion density are sensitive enough to detect changes in mental health over time. Method The conceptual framework for this study is our early illness detection model that was revised to be more easily applied to mental health issues. Changes in activity patterns are often the precursor to deteriorating health and mental health conditions ${ }^{1}$. Late recognition can hamper treatment responsiveness and impacts the well-being of older adults. Within the sensor network, data are logged from PIR-motion sensors which capture motion events as people move around the home. If there is continuous motion, the sensor will generate events at 7 second intervals. Sensors are obtained off-the-shelf and programmed to generate events at this time intervals. If there is less activity events will be generated less frequently. A web application displays the data as activity density maps showing events per hour, with hours on the vertical axis and progressive days on the horizontal axis. Color and intensity provide textural indications of time spent away from home and activity level. Texture features from the co-occurrence matrix are used to capture the periodicity pattern of the activity (including homogeneity, local variation, and entropy) and combined with the average motion density per hour and the average time spent away from home ${ }^{2}$. The similarity of two different density maps is represented by a number that is computed in feature space as the distance from one map to the other, in other words dissimilarity is being measured. Density maps were compared retrospectively with health assessment information (GDS, MMSE, and SF-12) to determine congruence between activity pattern changes and health information ${ }^{3}$. A case study method analyzed the density maps of individuals with identified mental health issues. These density maps were reviewed, along with the dissimilarity measures, to determine if the activity patterns reflected changes in mental health conditions (Figure 1). Results \& Discussion The motion density maps show visual changes in a person's activity, including circadian rhythm, time away from home, and general activity level (sedentary vs. puttering). The measures are sufficiently sensitive to yield dissimilarity measures that indicate significant change. This pilot study demonstrated that density maps can be used as a tool 

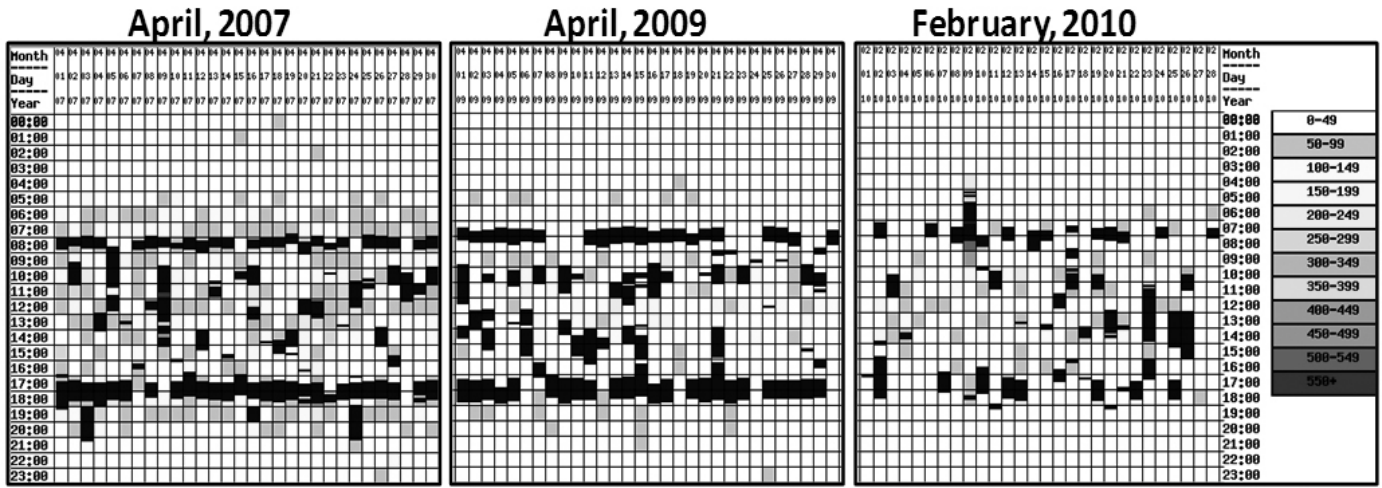

Figure 1. Density Map segments for a resident exhibiting increased depression over time. The dis-similarity (distance) measure is 0.32 for April, 2009 and 0.48 for February, 2010

for early-illness detection and points to the potential of sensor technology to improve traditional healthcare assessments and care coordination.

\section{References}

1. Rantz MJ, Marek KD, Aud MA, Johnson RA, Otto D, Porter R. TigerPlace: A New Future for Older Adults. Journal of Nursing Care Quality 2005;20(1):1-4

2. Wang S. Change Detection for Eldercare Using Passive Sensing, PhD dissertation, University of Missouri; 2011

3. Wang S, Skubic M, Zhu Y, Galambos C. Using passive sensing to estimate relative energy expenditure for eldercare monitoring. IEEE International Conference on Pervasive Computing and Communications,

March 2011:598-604; doi:10.1109/PERCOMW.2011.5766968

Keywords: early illness detection, sensors, density mapping, dementia, depression

Affiliation: University of Missouri, Columbia, USA; E: galambosc@missouri.edu

Full paper: No

\section{S. SUNDARRAO, D. DEKKER. Sensor integrated recreational technologies to monitor elderly.}

Gerontechnology 2012;11(2):274-275; doi:10.4017/gt.2012.11.02.140.00 Purpose Maintenance of balance requires the coordination of sensory, neural, and musculoskeletal systems. Many of these systems deteriorate as people age. This has the potential to affect balance, restrict safe mobility, increase the likelihood of a fall and adversely affect the quality of life. Exercise interventions with balance and muscle strengthening components have been shown to reduce falls and be effective in improving balance among the elderly ${ }^{1}$. Incorporation of technologies used in sports medicine and recreation, commercial video games and the development of micro-electro-mechanical systems (MEMS) technologies offer the ability to monitor elderly as they participate in leisure activities ${ }^{2,3}$. By taking advantage of the advancements in microelectronics it has been possible to build instrumentation that is small enough to be unobtrusive for a number of sporting and clinical applications ${ }^{4}$. One such technology that has seen rapid development in recent years is in the area of inertial sensors ${ }^{5,6}$. These sensors respond to minute changes in inertia in the linear (accelerometers) and radial directions (rate gyroscopes). Methods Fabricating the new device requires simple tools such as a paper cutter and a painting knife. By contrast, silicon MEMS-sensors require complicated, days-long microlithography processes orchestrated in clean-room settings. But silicon devices also perform better, measuring forces smaller than $80 \mu \mathrm{N}$ compared with $120 \mu \mathrm{N}$ for the paper sensors. The paper sensor, which is a bit larger than a dime (or a 2-euro-cent coin), is a cantilever cut out from thick chromatography paper, which is normally used for chemistry experiments. At the base of the cantilever is a U-shaped piece of carbon and silver contact pads. Carbon and silver contact pads are screen printed on the cantilever's base using graphite and silver inks and stencils cut out of vinyl film. A force applied to the cantilever bends it and stresses the carbon piece, changing its resistance. In piezoresistive silicon sensors, the resistance change is typically measured using an electrical circuit called a Wheatstone bridge, which is fabricated on a chip along with the MEMS-device. Simply glu- 
ing resistors at appropriate locations and then connecting them into the circuit using silver ink constructs the bridge circuit on paper. Results and Discussion These sensitive MEMS-devices cost a few dollars and are just a few millimeters in size, replacing bulky, multi-component deployment system that cost more than US \$50. The new device emulates the piezoresistive silicon MEMSsensors that are at the heart of many modern accelerometers. The right amount of technical sophistication and making sensors as inexpensive as possible can be an alternative when super sensitivity is not necessary such as in applications for monitoring balance and coordination.

\section{References}

1. Sherrington C, Whitney JC, Lord SR, Herbert RD, Cumming RG, Close JCT. Effective exercise for the prevention of falls: a systematic review and meta-analysis. Journal of the American Geriatrics Society 56(12):2234-2243; doi:10.1111/j.1532-5415.2008.02014.x

2. Bao L, Intille SS. Activity recognition from user annotated acceleration data. Proceedings $2^{\text {nd }}$ International Conference on Pervasive Computing 2004;1-17; doi:10.1007/978-3-540-24646-6_1

3. Matthew CE. Calibration of accelerometer output for adults. Medicine \& Science in Sports \& Exercise 2005;37(Supplement):S512-S522; doi:10.1249/01.mss.0000185659.11982.3d

4. James DA, Davey N, Rice T. An accelerometer based sensor platform for athlete performance analysis. Proceedings of IEEE Sensors 2004;3:1373-1376

5. Troiano RP. A timely meeting: objective measurement of physical activity. Medicine \& Science in Sports \& Exercise 2005;37(Supplement):S487-S489; doi:10.1249/01.mss.0000185473.32846.c3

6. Welk GJ. Principles in design and analyses for the calibration of accelerometry-based activity monitors. Medicine \& Science in Sports \& Exercise 2005;37(Supplement):S501-S511;

doi:10.1249/01.mss.0000185660.38335.de

Keywords: integrated sensors, elderly, sports and recreation

Affiliation: University of South Florida, Tampa, Florida, USA; E: sundarra@usf.edu

Full paper: No

\section{T. HAYES, J.A. KAYE, M. PAVEL, H. JIMISON. The human activity project: What behavioural markers}

teach us about important health changes? Gerontechnology 2012;11(2):275; doi:10.4017/ gt.2012.11.02.111.00 Purpose To describe how in-home sensors are being used to understand behavioural changes in seniors, and to relate these behavioural changes to important health changes. Method The Oregon Center for Aging and Technology conducts a range of observational and interventional in-home studies which use technology to capture behavioural markers that provide significant insights into the health status of seniors. While smart home technologies are in common use in demonstration projects, it has been difficult to gather the evidence that these technologies accurately reflect both behavioural and health changes. Using data gathered in hundreds of homes over the past four years, we have been able to both refine our sensor algorithms to capture key behaviours of interest, and to look at changes in these behaviours in the context of other health changes ${ }^{1}$, particularly cognitive decline. Results \& Discussion We have found that long-term monitoring of the trajectory of unobtrusively monitored computer use can distinguish seniors with mild cognitive impairment $(\mathrm{MCl})$ from healthy controls. Similarly, trajectories of walking speeds over time separate $\mathrm{MCl}$ subjects from healthy seniors. Furthermore, even among $\mathrm{MCl}$-subjects, we have found that differences in sleep patterns can separate those with amnestic $\mathrm{MCl}$ from those with non-amnestic $\mathrm{MCl}$. While these and related results are very promising, the field continues to need better focus on creating the objective evidence of what approaches work best. In this presentation we will talk about these results in the framework of such opportunities for the future.

\section{References}

1. Kaye JA, Maxwell SA, Mattek N, Hayes TL, Dodge H, Pavel M, Jimison HB, Wild K, Boise L, Zitzelberger LA. Intelligent Systems for Assessing Aging Changes: Home-Based, Unobtrusive and Continuous Assessment of Aging. The Journals of Gerontology Series B: Psychological Sciences and Social Sciences 2011;66B(Supplement 1):i180-i190; doi:10.1093/geronb/gbq095

Keywords: housing and daily living, predicting health changes, cognitive impairment Affiliation: Oregon Health \& Science University, Portland, OR, USA; E: hayesta@ohsu.edu Full paper: No 